\title{
Squamous Epithelium in Respiratory Tract of Children with Tracheo-oesophageal Fistula
}

\author{
JOHN L. EMERY and ANWAR J. HADDADIN \\ From The Department of Pathology, Children's Hospital, Sheffield
}

\begin{abstract}
Emery, J. L., and Haddadin, J. (1971). Archives of Disease in Childhood, 46, 236. Squamous epithelium in respiratory tracts of children with tracheooesophageal fistula. Histological study of the trachea and bronchi from 50 children dying with tracheo-oesophageal fistula showed that in $80 \%$ there was extensive squamous metaplasia. This change was chiefly in the posterior muscular wall of the trachea, but frequently extended to the lateral and anterior walls of the trachea, and into the bronchi. It is suggested that the primary localization to the muscular trachea is related to the embryology of the congenital deformity, and that secondary factors such as acute infection and oxygen therapy may extend the lesion. The lesion is probably an important factor in the respiratory complications of children with tracheo-oesophageal fistula.
\end{abstract}

Tracheo-oesophageal fistula is one of the major congenital anomalies confronting the paediatric surgeon, but factors such as immaturity, associated anomalies and respiratory tract complications still too frequently lead to death. Of fatal complications, that termed 'pneumonia' is the most prominent (Cozzi and Wilkinson, 1967). The proportion of children dying in this way varies. Slim and Bickers (1970) give 75\%; Swenson et al. (1962) give $50 \%$; Waterston, Bonham-Carter, and Aberdeen $(1962,1963)$ found it between $28 \%$ and $56 \%$, depending on birthweight and time of operation. Death rates are, of course, also greatly influenced by the maturity of the child and the presence of other congenital deformities (Cole and BarrattBoyes, 1962; Cozzi and Wilkinson, 1967).

For a number of years we have noted the presence of squamous epithelium in the tracheas of children dying with tracheo-eosophageal fistulas and have collected material with the aim of assessing its incidence, extent, cause, and clinical importancethe objective of the present report.

\section{Material and Methods}

The materials studied comprised 50 necropsies carried out at the Sheffield Children's Hospital during the years 1958-1969 on children with tracheooesophageal fistula. On these children complete necropsies were carried out and, in 35, serial blocks of

Received 12 October 1970. approximately $2 \mathrm{~mm}$ thickness were taken throughout the length of the larynx, trachea, main bronchi, and oesophagus after the whole had been fixed undissected. In the remaining 15 cases, only random blocks were taken. As a control series, 400 sections of the midtrachea were drawn randomly from the files.

The whole of the material was studied from the point of view of the type of epithelium and its distribution. The results of these findings were analysed in relation to the age at death and the medical and surgical treatment that had been carried out on the children.

\section{Histological Criteria}

It is not always easy to differentiate between the epithelium of the trachea that has been slightly altered by inflammatory change and that has lost some of its superficial ciliated epithelial cells, and epithelium undergoing metaplasia.

Particular care was thus taken to discount the local and immediate effects of local inflammatory change of the epithelium. In this study squamous epithelium has only been recorded when the most superficial cells have had their major alignment parallel to the basement membrane, and the layers between the surface and the basement membrane are increased to three or more and intercellular bridges (Bizzazzero bands) are obvious.

The epithelium of the trachea normally has a distinct basement membrane having an outer homogeneous layer and a deeper layer of collagen merging with the underlying tissues. There is a basal layer of cells with extensive contact with the basement membrane. The ciliated epithelial cells all reach the surface and have an attachment to the basement membrane. The goblet 
cells also have a basement membrane attachment but may, or may not, reach the surface. A fourth type of cell is localized just outside tie basal cells and in close contact with them-the intermediate cells. These cells vary greatly in number in different areas. They seem to differ from all of the other cells in not having a direct attachment to the basement membrane. These cells are apparently derived from the basement cells (Rhodin, 1966; see Fig. 1).

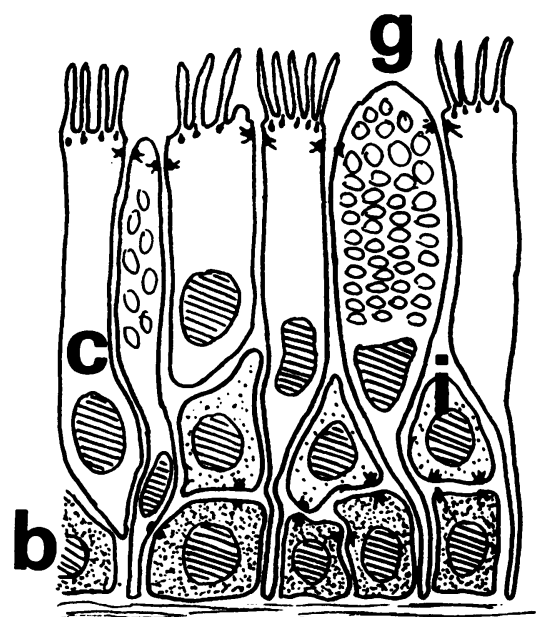

FIG. 1.-Diagrammatic representation of the normal tracheal epithelium (after Rhodin) showing basal cells (b), intermediate cells $(i)$, goblet cells $(g)$, and ciliated cells $(c)$.

When tracheal epithelium undergoes squamous metaplasia the ciliated and goblet cells are absent and the intermediary cells increased in numbers. These cells show varying forms sometimes showing a prickle cell picture as in skin, the outer cells show varying degrees of stratification and occasionally reach the stage of cornification. The basement membrane often becomes less distinct.

\section{Results}

Twenty-five ( $71 \%$ ) of the 35 cases from which serial blocks were available showed the presence of squamous type epithelium. In the remaining 15 from which random blocks of the trachea were available, squamous change was seen in 7 (46\%).

The longitudinal extent of the altered epithelium within the trachea is shown in Fig. 6 where it was seen that in 8 cases squamous epithelium occurred throughout the whole length of the larynx to the bronchi, in 2 from the larynx to the carina, and in a further 3, from the larynx to the site of the fistula. In 3 cases, the squamous epithelium extended from the level of the lower end of the upper pouch to the bronchi and in 4 cases was confined, in the

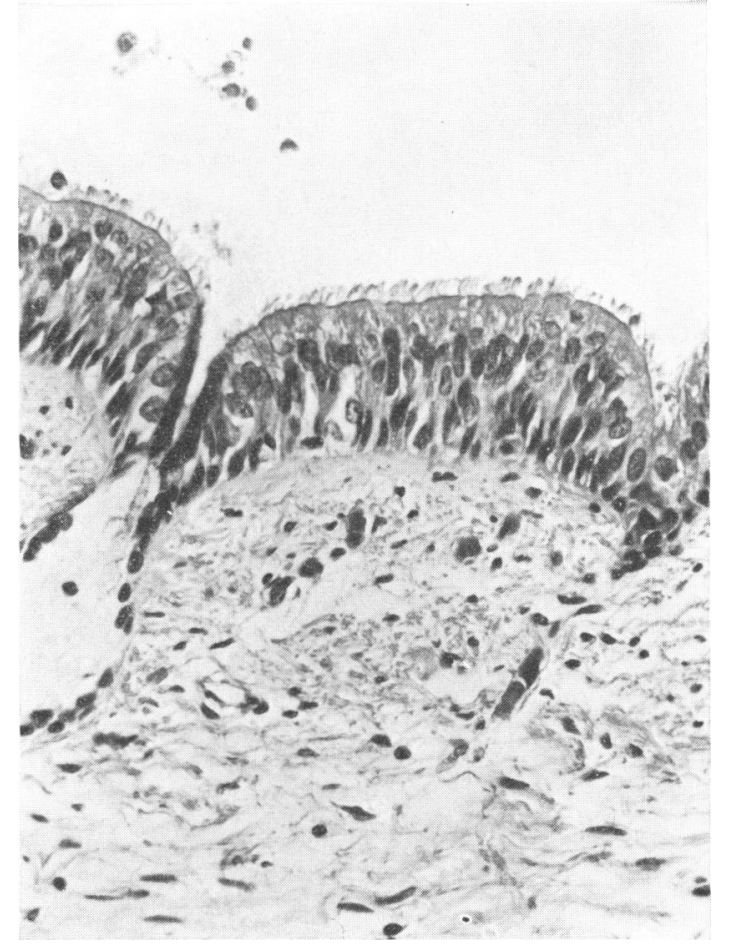

FIG. 2.-Normal tracheal epithelium. Note the presence of a full brush border of cilia, and that the cells are distinctly aligned to the basement membrane. $H$. and $E$. $\times 295$.)

trachea, to that part of the trachea adjacent to the upper oesophageal pouch but not extending to the site of the fistula lower in the trachea.

In 3 cases the squamous change was only noted in the trachea adjacent to the entry point of the fistula, and in 2 cases it extended from the fistula into the major bronchi. This type of analysis was only possible in those tracheas where serial blocks were available. In the trachea where an isolated section across the trachea at the level of the mid-trachea was available, a squamous change was seen in 7 of 15 cases, i.e. $48 \%$.

The incidence of epithelial change varied at different levels. In the trachea at the level of the thyroid it occurred in $52 \%$; in the mid-trachea at the level of the end of the upper pouch in $80 \%$; at the fistula site in $84 \%$; at the level of the carina in $60 \%$; and in the main bronchi in $52 \%$. In sections of the lungs from these same children, the epithelium extended to the smaller air passages in $26 \%$. The site of principal change is thus the mid-trachea at and above the level of the fistula. There is apparently a progressive diminution 


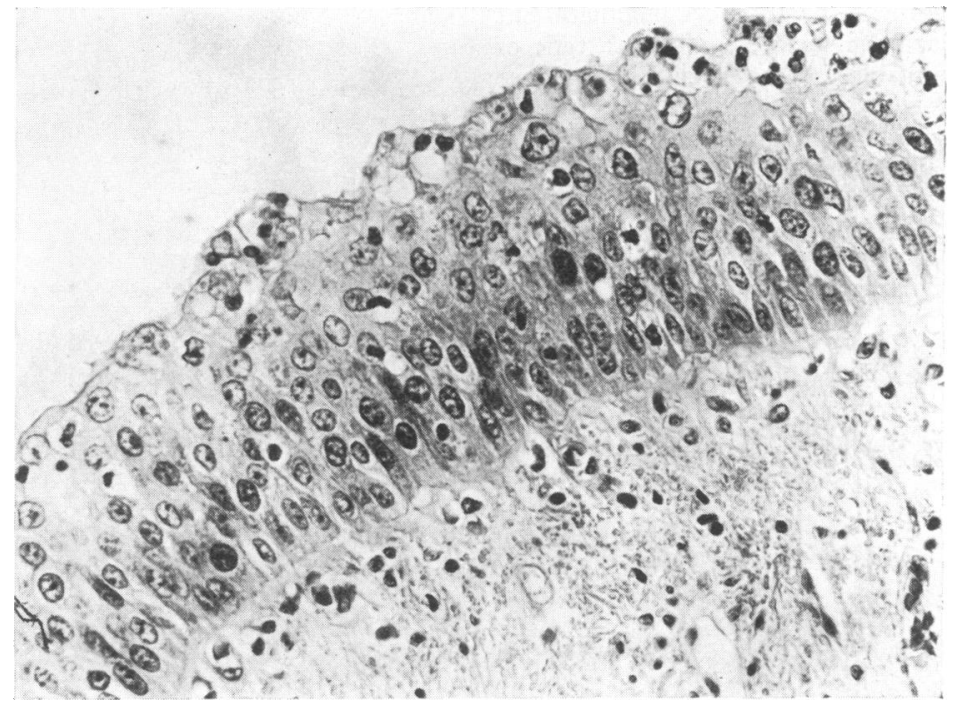

Fig. 3.

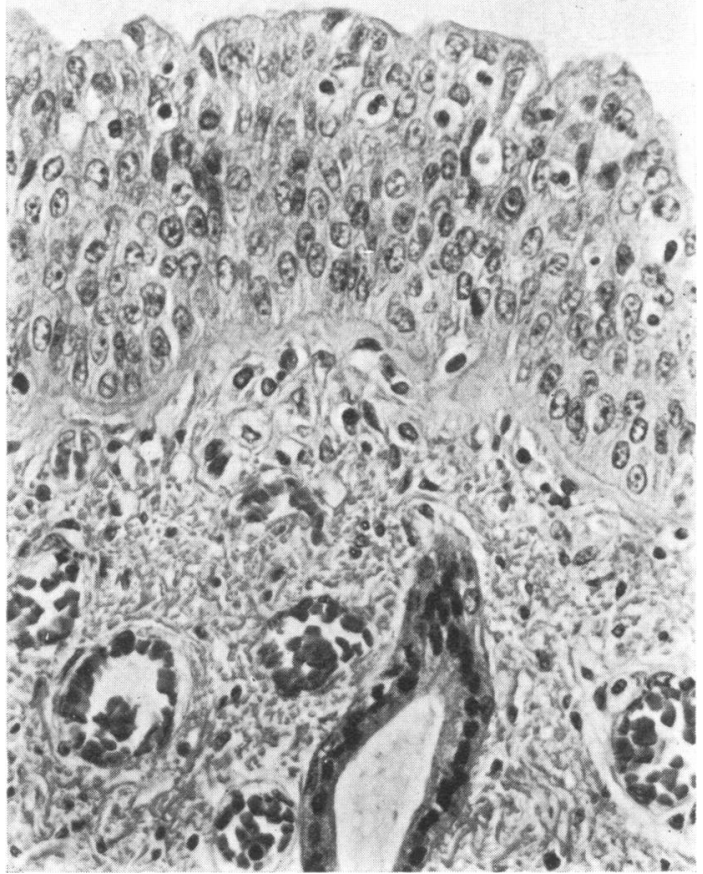

Fig. 4.

Fig. 3 and 4.-Tracheal epithelium that has undergone transformation. Note the great thickening of the epithelium due, apparently, to an increase in the number of intermediate cells, and the complete absence of ciliated epithelium. (H. and E. $\times 295$.) 


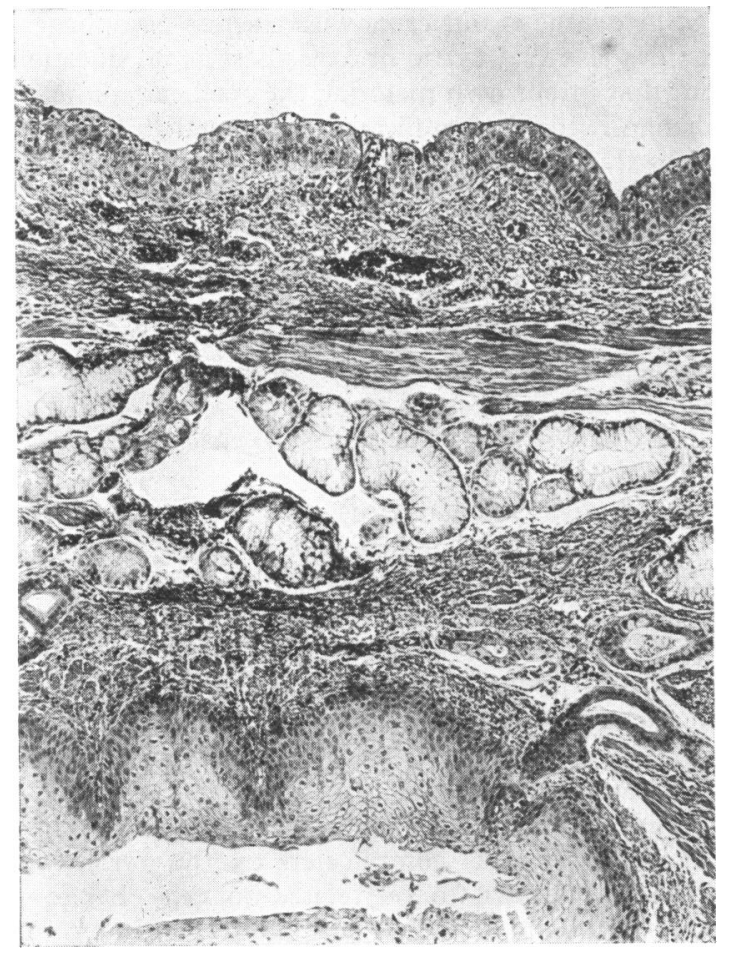

Fig. 5.-Section through the lower trachea just distal to the entry of the tracheo-oesophageal fistula. The wall of the oesophagus is seen in the lower part of the photograph above the mucus glands communicating with the oesophagus, the transverse bundles of muscle fibres, and above that, tracheal epithelium of a squamous type. (H. and $E . \times 70$.)

throughout the lower trachea, main and peripheral bronchi.

Regarding the circumferential distribution of abnormal epithelium, if squamous type change was present, it was always present within the posterior muscle area. In 10 of the 32 cases of the 50 studied, the change was confined to the muscular trachea; in a further 13 it extended approximately half way from the membranous area around the perimeter towards the anterior line of the trachea and in a further 9 the whole of the trachea was, at some point, completely surrounded by squamous epithelium.

Of the 50 cases, one only showed cornification, shedding non-nucleated squames. A brief history of this case follows.

\section{Case Report}

This child was born at term by normal delivery. No antenatal history is available. Tracheo-oesophageal fistula was diagnosed shortly after birth and he was transferred to Sheffield Children's Hospital the same day. He appeared well but had very coarse râles in the lung fields. The same day a thoracotomy was performed and the fistula resected and a primary anastomosis performed. Eight days after the operation he was still being tube fed but appeared to be recovering well and at no time required oxygen. It was noticed that saliva did not go down through the pharynx smoothly and an oesophageal stenosis was suspected.

After oesophagoscopy he developed stridor and dyspnoea, requiring intermittent oxygen, and three days later the lungs showed consolidation of the right upper lobe. As he required frequent sucking out, a tracheostomy was carried out but the tracheostomy tube became blocked frequently; despite this he began to make quite good progress. When aged 8 weeks, he 'collapsed and died'. The tracheostomy tube appeared to be patent. Clinically, death was ascribed to 'acute chest infection'.

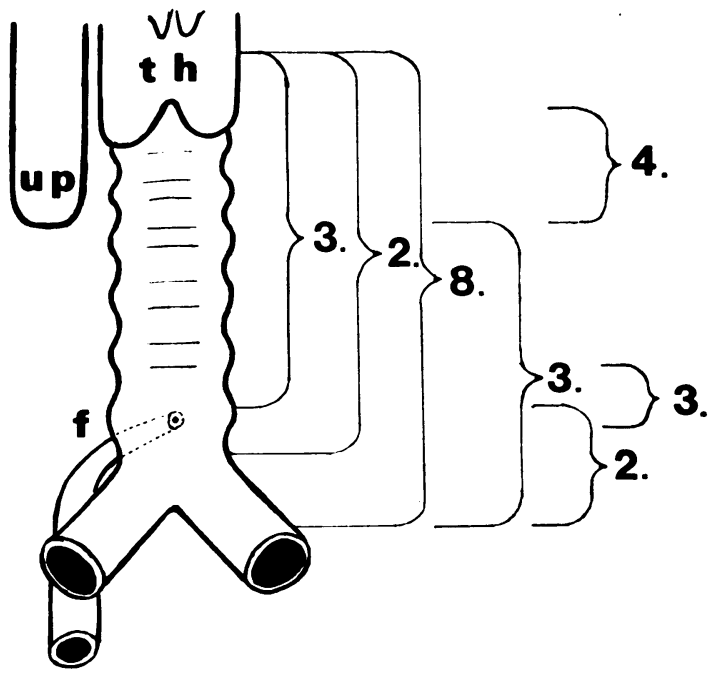

FIG. 6.-Diagram giving the extent of epithelial change found in serial blocks from 35 tracheo-oesophageal fistulas related to the site of the fistula $(f)$, upper pouch (up) and thyroid $(t h)$.

Trachea. There was a tracheitis. Virtually the whole of the upper trachea was lined by stratified squamous epithelium (Fig. 7).

Lungs. There was no pneumonia. Alveoli and air tubes contained large numbers of what were almost certainly shed alveolar epithelial cells. The alveoli were almost airless, apparently due to resorption beyond air passages obstructed by cells and mucus. The cause of death appeared to be inability to eliminate cell debris and mucus from the lower air passages. 


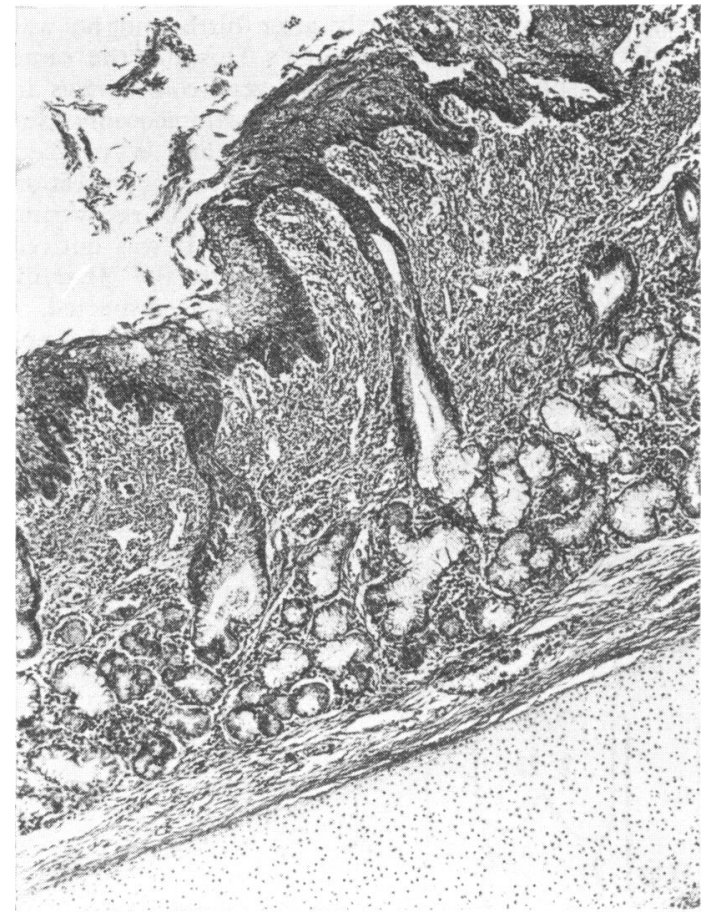

FIG. 7.-Trachea showing squamous epithelium shedding keratinized squames. (Masson's trichrome. $\times 49$.)

In the 400 control tracheas, some form of mucosal metaplasia was seen in 10 cases $(2.5 \%)$, being present in the muscular wall alone in 2 , extending to the lateral wall in 3, and to the whole perimeter in 5. The appearance of the epithelium in these 10 cases differed in no obvious way from that seen in the children with tracheo-oesophageal fistula: the 10 cases included children dying with cystic fibrosis of the pancreas and chronic lung infection.

\section{Discussion}

The questions that immediately arise are: are we seeing a congenital anomaly in growth, or a metaplasia of previously normal ciliated epithelium; and is the incidence of this change significantly greater than in other children ?

Regarding the incidence of squamous metaplasia in children without tracheo-oesophageal fistulas, our own study showed an incidence of $2.5 \%$. These cases include children with cystic fibrosis which accounts for between 2 and $3 \%$ of necropsies, but also included two children without the latter condition and in whom the question of oxygen therapy could be excluded; these cases are being studied further.
Since none of our cases with tracheo-oesophageal fistulas also had cystic fibrosis there is no question but that in our own material, the tracheal epithelial change is highly significantly increased in children with tracheo-oesophageal fistula. Regarding the incidence of squamous metaplasia in infants, published figures do not help greatly. The youngest case showing metaplasia in Zeuler and Newton's study (1949) was aged 6 weeks. Children's respiratory tracts have been surveyed by workers in the field of cancer research looking for metaplasia, changes of carcinoma in situ, and the effects of smoking (Weller, 1953; Auerbach et al., 1960).

Small areas of metaplasia are apparently present when the whole bronchial tract is studied in up to $32 \%$ of people of all ages, with significant increase in persons with chronic inflammatory conditions of the lung and with lung cancer. All these lesions described, however, consist of small isolated areas of metaplasia in individual sections and not to large areas of the trachea as seen in tracheooesophageal fistula.

The question of primary deformity and secondary metaplasia is complicated by the variety of conditions known to be related to this changenotably vitamin A deficiency, chemical and physical trauma, humidity of air, virus infection, chronic infection of the lung (tuberculosis, bronchiectasis, staphylococcal infection), metabolic states such as uraemia, cystic fibrosis of the pancreas, congenital cystic lesions of lung, and, of most recent interest, oxygen therapy.

In children with tracheo-oesophageal fistula who survive for weeks and months, many of these factors must be present but many can also be excluded. These children show no evidence of vitamin A deficiency in any other tissues such as the cornea. Of the 25 children with abnormal epithelium, 18 died between the ages of 4 hours and 4 days, a number of the early deaths being in children dying from other deformities and with no histological evidence of infection of the respiratory tract, and without having received oxygen therapy or intubation. The role of oxygen therapy is difficult to evaluate in the older deaths, as most of these children received oxygen terminally, often by endotracheal tube or tracheostomy. But the occurrence of an identical picture in children who did not receive oxygen suggests that it was not likely to be a primary factor. The same argument holds for virus diseases and chronic infection, while cystic fibrosis could be excluded on histological grounds.

One factor that we cannot exclude in these 


\section{Squamous Epithelium in Respiratory Tract of Children with Tracheo-oesophageal Fistula 241}

children is the possible effect of persistent and repeated reflux of gastric contents through the fistula from the stomach. We know, from the presence of vernix in the meconium, that these infants must have been freely swallowing amniotic fluid through their tracheas. However, this cannot be of great importance, for the presence of vernix in the lungs does not seem to irritate in any way the infant's lung, and there exists a free movement of amniotic fluid in the respiratory tract in the normal fetus. The gastric contents at birth, apart from ingested vernix, seem to be chiefly locally secreted mucus which, while capable of obstructing the respiratory tract, seems to be non-irritant. This, of course, will not apply after birth.

The high incidence, in our cases, of altered epithelium in the posterior wall of the trachea above the fistula suggests that there is an embryonic factor operating, with the inclusion of some oesophageal anlage within the trachea. The embryology of tracheo-oesophageal fistulas has been extensively studied by Smith (1957). The normal development of the trachea starts in the 21-day-old embryo by the appearance of the respiratory primordium in the mid-line of the ventral wall of the foregut between the thyroid primordium cranially and the intestinal portal caudally. A cellular proliferation produces a ridge on the external surface of the foregut and a corresponding mid-line groove, the laryngo-tracheal sulcus, on the internal surface where the epithelium consists of two to three layers and signs of striation to form cilia start to appear. In the 25th-day embryo the tracheo-oesophageal septum starts to appear. Ridges of endodermal cells develop from the lateral wall at the caudal end of the lung-bud region of the foregut. The union of these proliferating ridges within the lumen of the foregut divides it into a ventral respiratory and a dorsal digestive portion. By the age of 34-36 days, separation of the lung and trachea from the foregut is essentially complete. The tracheo-oesophageal septum will form the membranous part of the trachea.

While this is taking place, the lateral eosophageal grooves, as described by Forssner in 1907 and Lewis in 1912, start to develop, one on each lateral side of the oesophagus, that runs from just dorsal to the laryngotracheal sulcus to the dorsal wall of the oesophagus. It is the overgrowth of these ridges that causes the tracheo-oesophageal fistula. It is, therefore, not by chance that the membranous part of the trachea showed the highest involvement. The tracheo-oesophageal fistula is formed by the overgrowth of the lateral oesophageal ridges that divide the oesophagus and, by so doing, may incorporate part of the oesophagus in the posterior wall of the trachea. This also explains both why the fistula site has the highest incidence of squamous epithelium, and why squamous epithelium is found in that part of the trachea at the level of the upper pouch of the oesophagus, because these are the sites where the embryological deviation occurred.

The effects of the loss of ciliated epithelium from the trachea are obvious. A film of mucus swept along by the cilia is one of the essential scavenger and anti-infection mechanisms of the lung (Carson, Goldhamer, and Carpenter, 1966; Stuart-Harris, 1966). The presence of extensive non-ciliated epithelium in the trachea of a proportion of children with tracheo-oesophageal fistulas is likely to have a profound effect on the viability of these children.

Not all such cases necessarily die in infancy, and in two studies of the late results of treatment of tracheo-oesophageal fistulas cases have been reported which could well have been suffering from an epithelial deformity. Among 9 cases 14 to 19 years after repair, Burgess, Carlson, and Ellis (1968) found 3 complaining of repeated respiratory tract infections, while Lind, Blanchard, and Guyda (1966) found 8 of 10 cases complaining of chronic wheezing cough.

The importance of this epithelial deformity in these children at the moment lies more in their general management than in the technical surgical approach. It seems to be as likely that these children are unable to remove cells and mucus from the lower respiratory passages and alveoli, and that if so, pulmonary lavage rather than simple intubation may be indicated. Also, if these children, as we suspect, have a reduced cilial bed in main air passages and trachea, the effects of minor degrees of oxygen irritation may have devastating results and produce a total block from mucus. The fact that in a number of the tracheas that we studied, the loss of ciliated epithelium had extended to the whole perimeter of the trachea, suggests that this could well have happened terminally.

Mr. A. J. Haddadin (present address: El Hussein Hospital, Salt, Jordan) is working under a grant from the British Council.

Photographs by Mr. A. Tunstill.

\section{REFERENCES}

Auerbach, O., Stout, A. P., Hammond, E. C., and Garfinkel, L. (1960). Microscopic examination of bronchial epithelium in children. American Review of Respiratory Diseases, 82, 640.

Burgess, J. N., Carlson, H. C., and Ellis, F. H., Jr. (1968). Esophageal function after successful repair of esophageal atresia and tracheoesophageal fistula. Fournal of Thoracic and Cardiovascular Surgery, 56, 667. 
Carson, S., Goldhamer, R., and Carpenter, R. (1966). Mucus transport in the respiratory tract. American Review of Respiratory Diseases, 93 (3, ii), Suppl., 86.

Cole, D., and Barratt-Boyes, B. G. (1962). Oesophageal atresia. New Zealand Medical fournal, 61, 267.

Cozzi, F., and Wilkinson, A. W. (1967). Oesophageal atresia. Lancet, 2, 1222.

Forssner, H. (1907). Die angeborenen Darm-und Osophagusatresien. Anatomische Hefte, 34, 1.

Lewis, F. T. (1912). The development of the oesophagus. In Manual of Human Embryology, vol. 2, p. 355 . Ed. by F. Keibel and F. P. Mall. Lippincott, Philadelphia.

Lind, J. F., Blanchard, R. J., and Guyda, H. (1966). Esophageal motility in the tracheoesophageal fistula and esophageal atresia. Surgery, Gynecology and Obstetrics, with International Abstracts of Surgery, 123, 557.

Rhodin, J. A. G. (1966). Ultrastructure and function of the human tracheal mucosa. American Review of Respiratory Diseases, 93 (3, ii), Suppl., 1.

Slim, M. S., and Bickers, W. M. (1970). Esophageal atresia with tracheoesophageal fistula. Archives of Surgery, 100, 577.
Smith, E. I. (1957). The early development of trachea and oesophagus in relation to atresia of the oesophagus and tracheooesophageal fistula. Contributions to Embryology, Carnegie Institution, 245, 43.

Stuart-Harris, C. H. (1966). Respiratory viruses, ciliated epithelium, and bronchitis. American Review of Respiratory Diseases, 93 (3, ii), 150.

Swenson, O., Lipman, R., Fisher, J. H., and DeLuca, F. G. (1962). Repair and complications of esophageal atresia and tracheoesophageal fistula. New England Fournal of Medicine, 267, 960.

Waterston, D. J., Bonham-Carter, R. E., and Aberdeen, E. (1962) Oesophageal atresia: tracheo-oesophageal fistula. A study of survival in 218 infants. Lancet, 1, 819,

Waterston, D. J., Bonham-Carter, R. E., and Aberdeen, E. (1963). Congenital tracheo-oesophageal fistula in association with oesophageal atresia. Lancet, 2, 55.

Weller, R. W. (1953). Metaplasia of bronchial epithelium. American fournal of Clinical Pathology, 23, 768.

Zeuler, W. W., and Newton, W. A., Jr. (1949).' The pathogenesis of fibrocystic disease. A study of 36 cases with special reference to the pulmonary lesion. Pediatrics, 4, 53. 